Open Access

\title{
The Influence of Hydrogen Gas Treatment on the Characteristics of ZnO Films
}

\author{
Lung-Chien Chen* and Ching-Ho Tien
}

Department of Electro-optical Engineering, National Taipei University of Technology, 1, sec.3, Chung-Hsiao E. Rd., Taipei 106, Taiwan, Republic of China

\begin{abstract}
This study presents a zinc oxide ( $\mathrm{ZnO}$ ) film deposited on a glass substrate by ultrasonic spraying pyrolysis. The $\mathrm{ZnO}$ nanostructure was formed by treating the as-deposited $\mathrm{ZnO}$ films with hydrogen. The root-mean-square (RMS) roughness increases from $5.83 \mathrm{~nm}$ to $12.53 \mathrm{~nm}$ during the treatment for $20 \mathrm{~min}$, but slightly decreases to $11.87 \mathrm{~nm}$ at a treatment time of $30 \mathrm{~min}$. In the range $400-500 \mathrm{~nm}$, the transparency of all the films with hydrogen treatment is slightly lower than that of the untreated films. The slight drop in the transparency of the films with hydrogen treatment is caused by scattering from pin-holes or nanostructures on the surface.
\end{abstract}

Key Words: Zinc oxide, hydrogen gas treatment, ultrasonic spraying pyrolysis.

\section{INTRODUCTION}

Because of having a wide direct band gap energy of 3.37 $\mathrm{eV}$ and a large exciton binding energy of $60 \mathrm{meV}$, zinc oxide $(\mathrm{ZnO})$ is regarded as a promising material for use in optical devices [1-3]. Therefore, $\mathrm{ZnO}$ film has been extensively used in light-emitting diodes (LEDs), laser diodes (LDs), ultraviolet (UV) detection devices, and other optoelectronic devices [3-9]. Moreover $\mathrm{ZnO}$ and related materials, which are doped with transition metal (TM) ions, have high-Curietemperature ferromagnetism such that it is expected to have applications in spintronics, information storage and data processing devices [10].

On the other hand, $\mathrm{ZnO}$ films with one-dimensional structures have attracted increasing interests because of their potential for use in nanometer-scale optoelectronic devices. The manufacture of the $\mathrm{ZnO}$ nanostructures by treating with hydrogen gas or hydrogen-containing gas has been reported [11-14]. However, the characteristics of the $\mathrm{ZnO}$ films with hydrogen treatment are still unclear. This work will investigate the characteristics of hydrogen-treated p-ZnO nanostructures. An N-In codoped p-type dopant was deposited on a glass substrate by ultrasonic spraying pyrolysis. The morphology and crystallinity of the $\mathrm{ZnO}$ films are studied. Finally, the optoelectronic properties of the $\mathrm{p}-\mathrm{ZnO}$ nanostructure formed by hydrogen treatment are elucidated.

\section{EXPERIMENTAL}

$\mathrm{N}$-In codoped $\mathrm{ZnO}$ films were deposited by ultrasonic spray pyrolysis at atmospheric pressure on glass substrates. Three aqueous solutions, $\mathrm{Zn}\left(\mathrm{CH}_{3} \mathrm{COO}\right)_{2} \cdot 2 \mathrm{H}_{2} \mathrm{O}(0.5 \mathrm{~mol} / \mathrm{l})$, $\mathrm{CH}_{3} \mathrm{COONH}_{4}(2.5 \mathrm{~mol} / \mathrm{l})$ and $\mathrm{In}\left(\mathrm{NO}_{3}\right)_{3}(0.5 \mathrm{~mol} / \mathrm{l})$, were used as sources of zinc, nitrogen, and indium, respectively.

*Address correspondence to this author at the Department of Electro-optical Engineering, National Taipei University of Technology, 1, sec.3, ChungHsiao E. Rd., Taipei 106, Taiwan, Republic of China; Tel: +886-2-27712171; Fax: +886-2-8773-3216; E-mail: ocean@ntut.edu.tw
The atomic ratio of $\mathrm{Zn} / \mathrm{N}$ was $1: 2$ in the $\mathrm{N}$-doped film, and that of $\mathrm{Zn} / \mathrm{N} / \mathrm{In}$ was 1:2:0.15 in the N-In codoped film [15]. Glass was used as the substrate, which was etched with $\mathrm{HCl}$ for $5 \mathrm{~min}$ before deposition. An aerosol of the precursor solution was generated by using a commercial ultrasonic nebulizer. P-type $\mathrm{N}$-In codoped $\mathrm{ZnO}$ films were obtained by heating the substrate to $650{ }^{\circ} \mathrm{C}$, and then $\mathrm{ZnO}$ films were carried out with a post-deposition annealing at $500{ }^{\circ} \mathrm{C}$ for 10 min in oxygen ambient to improve the film quality. Finally, the $\mathrm{ZnO}$ films were studied by Hall measurements. The ohmic contacts for electrical measurements were made by evaporating $\mathrm{Ni} / \mathrm{Au}$ alloy at the four corners of the samples using electron-beam evaporation technique at a base pressure of $1 \times 10^{-6}$ Torr. The hole concentration and mobility of p-ZnO were about $1 \times 10^{17} \mathrm{~cm}^{-3}$ and about $46 \mathrm{~cm}^{2} / \mathrm{V}-\mathrm{s}$, respectively. These results are consistent with those of Ref. [16]. The crystalline structure were studied by X-ray diffraction (XRD) using a rotating anode Rigaku x-ray powder diffractometer (Mac Science Corp. M03XHF, Japan) with $\mathrm{Cu}-\mathrm{K} \alpha_{1}$ radiation of $1.54056 \AA$, radiation generated at $40 \mathrm{kV}$ and $50 \mathrm{~mA}$, and the films had a polycrystalline structure.

$\mathrm{P}-\mathrm{ZnO}$ etching process was performed in hydrogen atmosphere and the morphology was studied by atomic force microscopy (AFM). A JEOL JSM-5600 scanning electron microscope (SEM) was used to study the surface morphology of the P-ZnO films. A 30-W deuterium lamp and a 35-W halogen lamp were used as light sources in the transmittance spectra studies at wavelengths from 300 to $800 \mathrm{~nm}$ and the optical band gap energy was calculated. All measurements were made at room temperature.

\section{RESULTS AND DISCUSSION}

The AFM was used to measure the surface roughness of the films over an area of $5 \mathrm{~cm} \times 5 \mathrm{~cm}$. Fig. (1) presents an AFM image of the p-type $\mathrm{ZnO}$ film, which was deposited on a glass substrate with hydrogen gas treatment at $450{ }^{\circ} \mathrm{C}$. The $\mathrm{ZnO}$ film with a thickness of about $1.0 \mu \mathrm{m}$ was formed on the glass substrate. As compared with the as-deposited 
films, the films with hydrogen treatment would increase the surface roughness. Fig. (2a) plots the root-mean-square (RMS) surface roughness of films. Fig. (2b) shows the carrier concentration of films for different treatment time. The RMS roughness increases from 5.83 to $12.53 \mathrm{~nm}$ during the treatment for $20 \mathrm{~min}$, but then it slightly decreases to $11.87 \mathrm{~nm}$ as the treatment continues for $30 \mathrm{~min}$. However, the carrier concentration increases with the increase in treatment time owing to the vacancy raise of oxygen. The $\mathrm{ZnO}$ film in an environment of hydrogen would be etched, according to the following reaction.
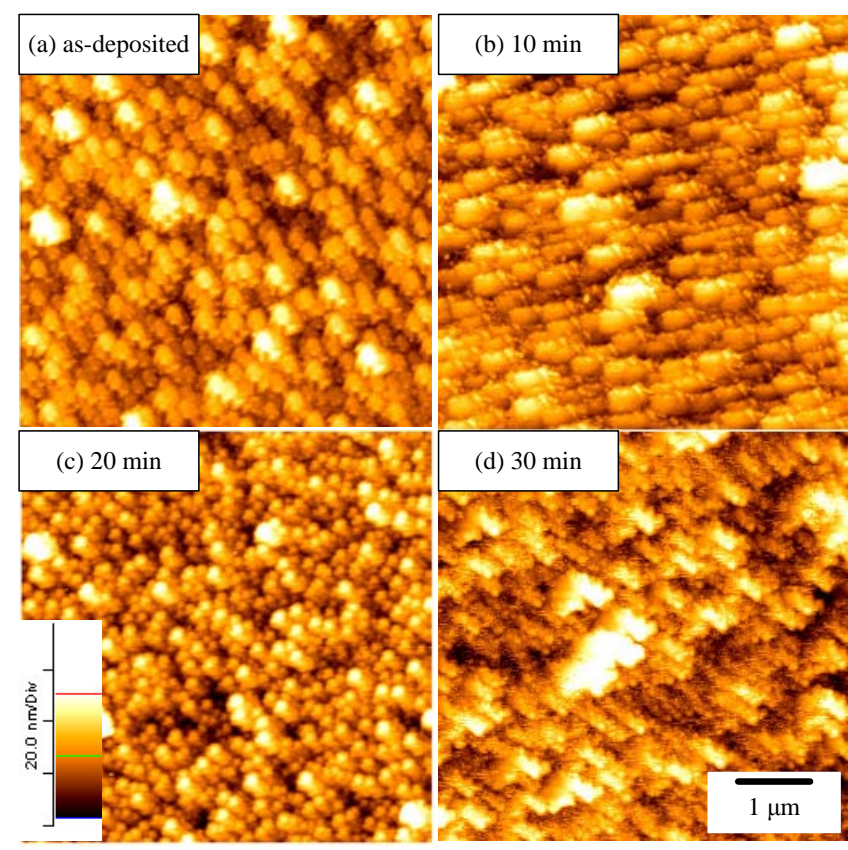

(d) $30 \mathrm{~min}$

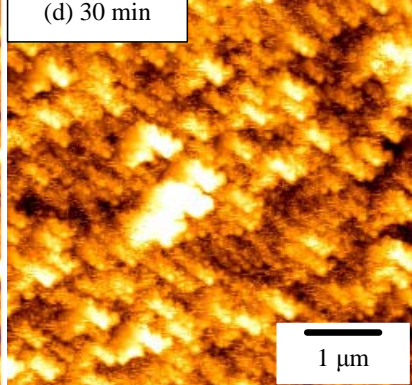

Fig. (1). The AFM image of the p-type $\mathrm{ZnO}$ film deposited on a glass substrate with hydrogen-gas treatment at $450{ }^{\circ} \mathrm{C}$.

$$
\mathrm{ZnO}+\mathrm{H}_{2} \rightarrow \mathrm{Zn}+\mathrm{H}_{2} \mathrm{O}
$$

Therefore, the $\mathrm{ZnO}$ film is roughened, as presented in Fig. (1). Fig. (3) shows the SEM micrographs of the $\mathrm{ZnO}$ films with nitrogen-gas treatment for different time. The micrographs indicate that the surface of the film consisted of small particles. The average particle sizes were approximately $0.1,0.12$, and $0.24 \mu \mathrm{m}$, respectively. The films with hydrogen treatment would increase the particle sizes. This result matched with that of AFM image.

Fig. (4a) plots typical results of the absorption experiment in the wavelength range $300-800 \mathrm{~nm}$. All of the films are highly transparent in the visible region. The optical transmittance in the visible range is $80-99 \%$, but is slightly lower film in the range $400-500 \mathrm{~nm}$ after hydrogen treatment. In the range $500-800 \mathrm{~nm}$, the light energy was well below the band gap of the films and the wavelength of the radiation markedly exceeds the grain size, the pin-hole size, and the surface roughness of the films. Therefore, in this range, no scattering occurs in the films and the loss of transparency is mainly due to the reflection of the light. However, in the range $400-500 \mathrm{~nm}$, the transparency of all the treated films is slightly lower, because of the electron transitions between the valence and conduction bands.
Additionally, radiation in the range $400500 \mathrm{~nm}$ can be scattered by smaller defects than by radiation with longer wavelengths. The slight drop in the transparency of the films with hydrogen treatment must be caused by the scattering from pin-holes or nanostructures on the surface. Fig. (4b) plots the absorption squared as a function of photon energy. The absorption coefficient $\alpha$ is expected to vary as $\alpha \propto$ $\left(\hbar v-E_{g}\right)^{1 / 2}$, where $E_{g}$ is the direct optical band gap. An extrapolation of the linear part of the curve to the horizontal axis in this figure yields the band-gap energy of $\mathrm{ZnO}$. All of the films have an absorption edge of $3.3 \mathrm{eV}$.

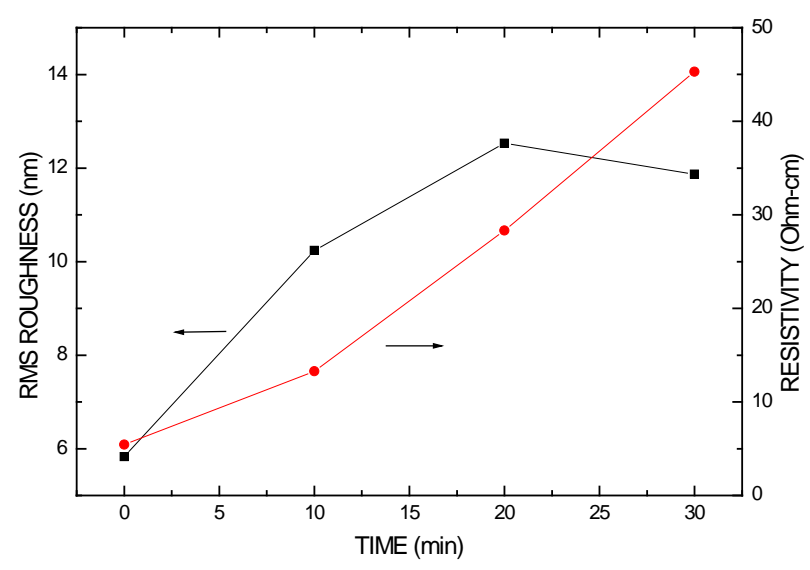

(a)

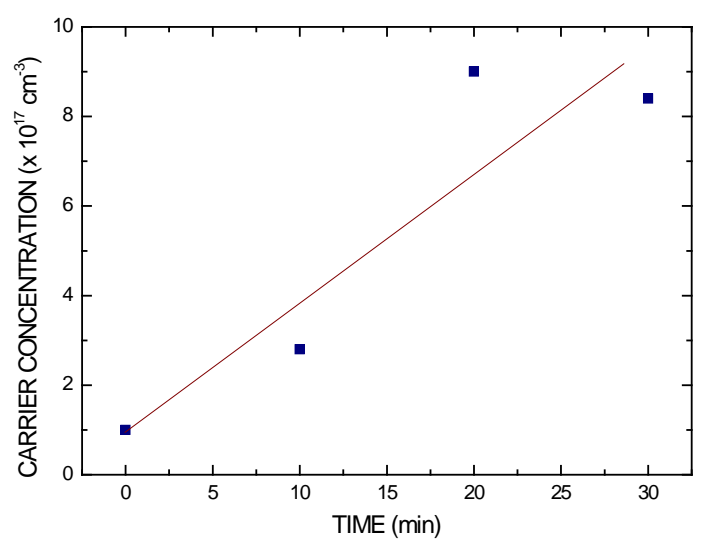

(b)

Fig. (2). (a) The RMS surface roughness and resistivity of films. (b) The carrier concentration of films.

Fig. (5) presents a typical XRD pattern of a $\mathrm{ZnO}$ film, which was deposited on a glass substrate prepared by ultrasonic spraying pyrolysis. Two dominant diffraction peaks, $\mathrm{ZnO}(002)\left(2 \theta=34.48^{\circ}\right)$ and $\mathrm{ZnO}(101)\left(2 \theta=36.34^{\circ}\right)$, are observed. The film had a polycrystalline (multiple phases) structure, which is barely changed by treatment with hydrogen.

\section{CONCLUSION}

$\mathrm{ZnO}$ films were deposited on glass substrates by ultrasonic spraying pyrolysis. The $\mathrm{ZnO}$ nanostructure 
was formed by treating the as-deposited $\mathrm{ZnO}$ films with hydrogen. The RMS roughness increases from 5.83 to 12.53 $\mathrm{nm}$ during 20-min treatment, but decreases slightly to 11.87 $\mathrm{nm}$ as the treatment continues for $30 \mathrm{~min}$. All of films had an absorption edge of $3.3 \mathrm{eV}$. However, in the range 400-500 nm, the transparency of all hydrogen-treated films is slightly lower than that of the untreated films. Scattering from pin-holes or nanostructures on the surface is responsible for the slight drop in the transparency of the films with hydrogen treatment.
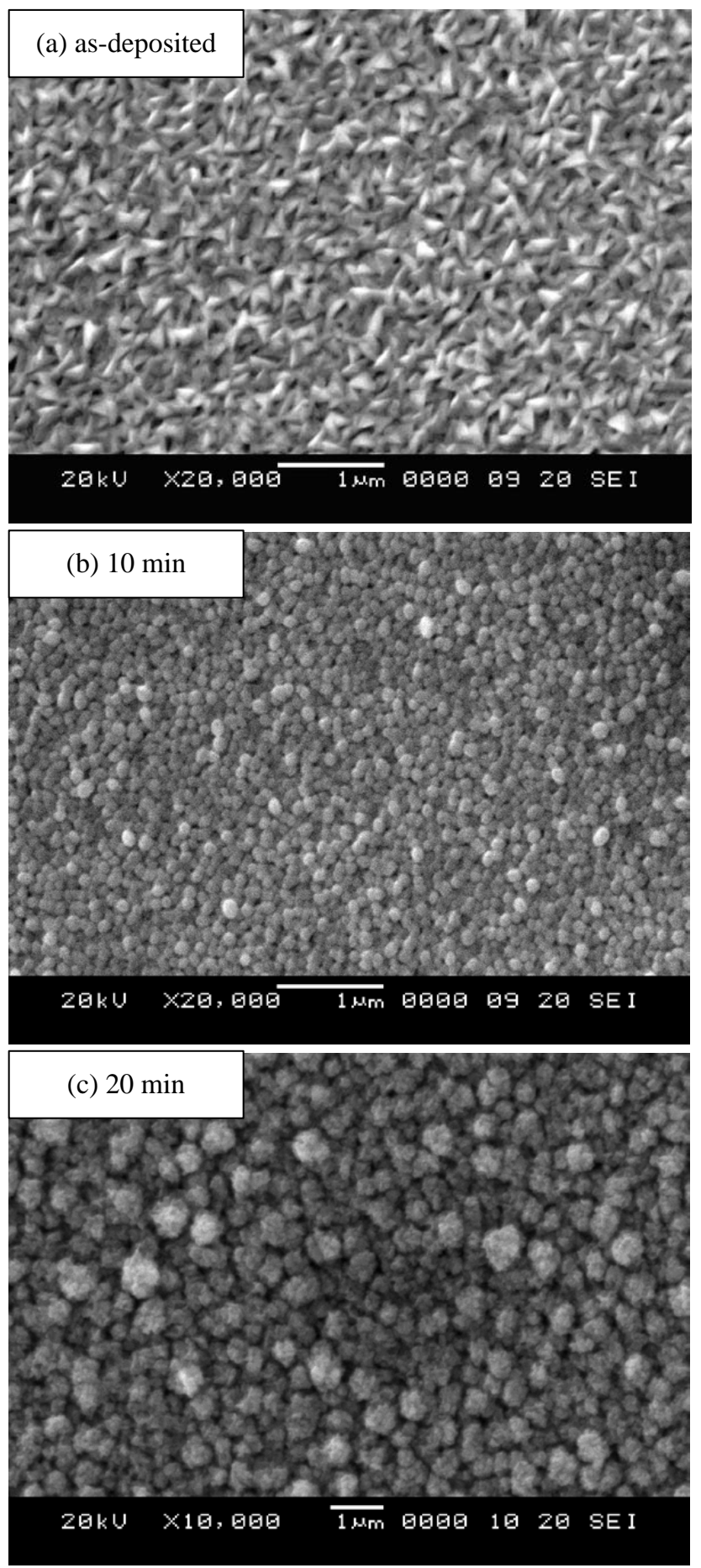

Fig. (3). SEM images of the $\mathrm{ZnO}$ films with hydrogen-gas treatment for: (a) 0, (b) 10, (c) $20 \mathrm{~min}$.

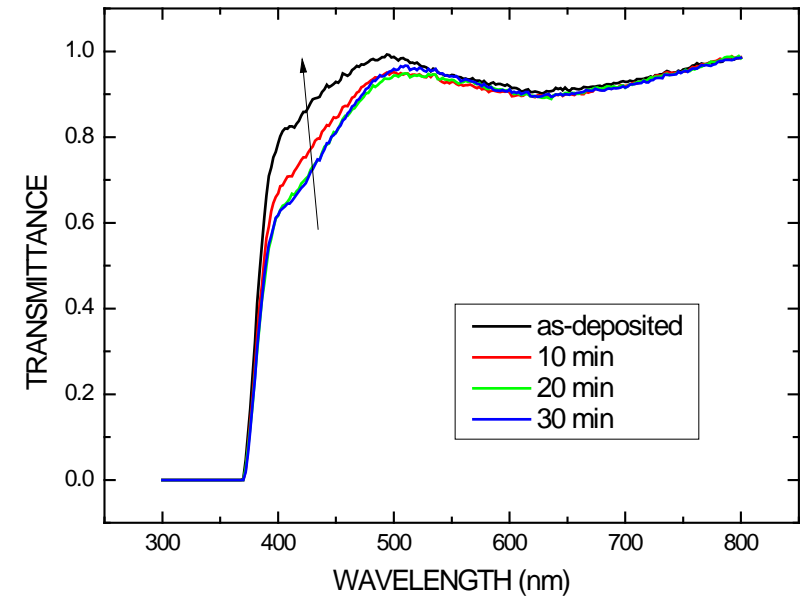

(a)

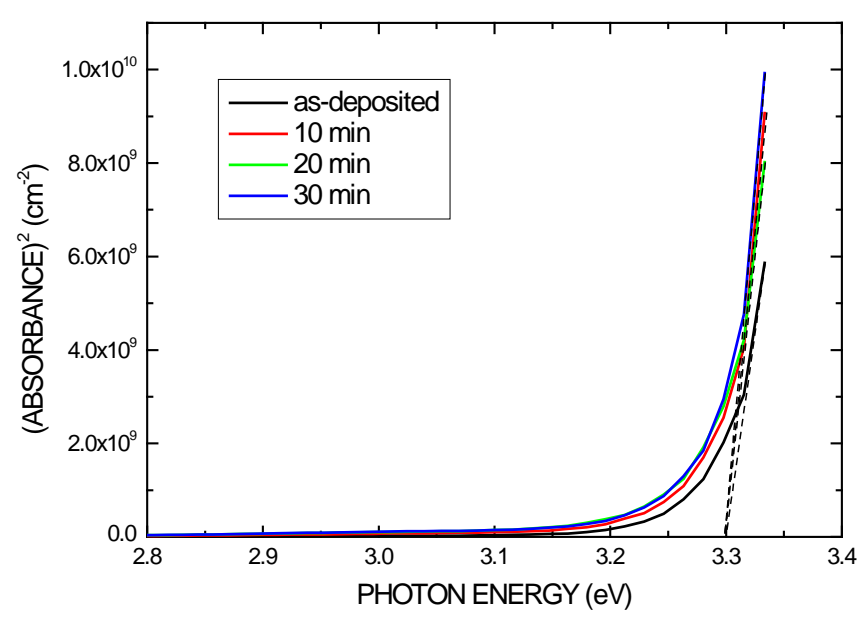

(b)

Fig. (4). (a) Typical absorption spectra experiment in the wavelength range of $300-800 \mathrm{~nm}$. (b) The relationship between absorption squared versus photon energy.

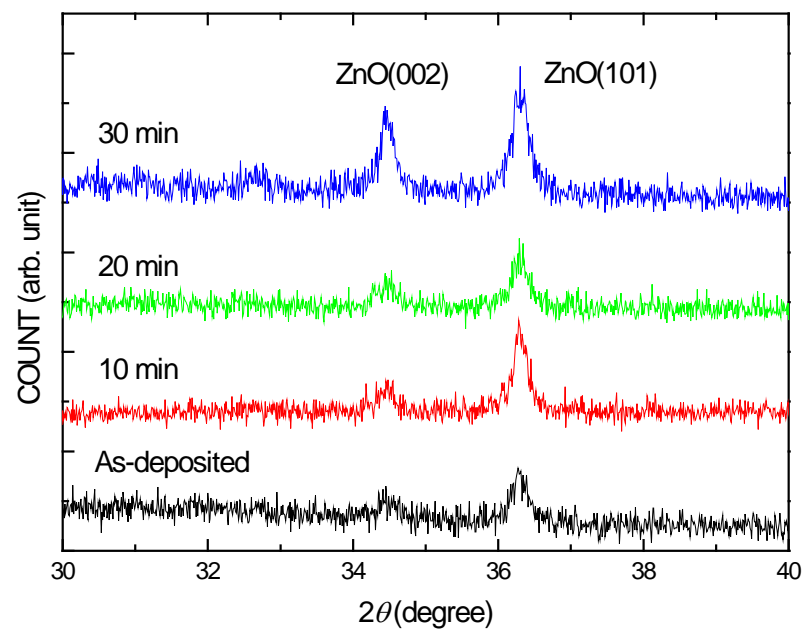

Fig. (5). Typical XRD pattern of $\mathrm{ZnO}$ film deposited on the glass substrate prepared. 


\section{ACKNOWLEDGEMENT}

Financial support of this work was provided by the National Science Council of the Republic of China under Contract No. NSC 95-2215-E-027-091.

\section{REFERENCES}

[1] Zhang XH, Chua SJ, Yong AM, et al. Exciton radiative lifetime in $\mathrm{ZnO}$ nanorods fabricated by vapor phase transport method. Appl Phys Lett 2007; 90: 013107.

[2] Danhara Y, Hirai T, Harada Y and Ohno N. Exciton luminescence of $\mathrm{ZnO}$ fine particles. Phys Stat Sol (c) 2006; 3: 3565-8.

[3] Lim JH, Kang CK, Kim KK, Park IK, Hwang DK and Park SJ. UV electroluminescence emission from $\mathrm{ZnO}$ light-emitting diodes grown by high-temperature radiofrequency sputtering. Adv Mater 2006; 18: 2720-4.

[4] Wei ZP, Lu YM, Shen DZ, et al. Room temperature $p$-n $\mathrm{ZnO}$ blueviolet light-emitting diodes. Appl Phys Lett 2007; 90: 042113.

[5] Leong ESP, Yu SF and Lau SP. Directional edge-emitting UV random laser diodes. Appl Phys Lett 2006; 89: 221109.

[6] Lee CW, Choi H, Oh MK, et al. ZnO-Based cyclodextrin sensor using immobilized polydiacetylene vesicles. Electrochem Solid State Lett 2007; 10: J1-3.

[7] Carotta MC, Cervi A, di Natale V, et al. $\mathrm{ZnO}$ gas sensors: A comparison between nanoparticles and nanotetrapods-based thick films. Sens Actuators B Chem 2009; 137: 164-9.
[8] Kong J, Chu S, Olmedo M, Li L, Yang Z and Liu J. Dominant ultraviolet light emissions in packed $\mathrm{ZnO}$ columnar homojunction diodes. Appl Phys Lett 2008; 93: 132113.

[9] Oja Acik I, Katerski A, Mere A, et al. Nanostructured solar cell by spray pyrolysis: Effect of titania barrier layer on the cell performance. Thin Solid Films 2009; 517: 2443-7.

[10] Dietl T, Ohno H, Matsukura F, Cibert J and Ferrand D. Zener model description of ferromagnetism in zinc-blende magnetic semiconductors. Science 2000; 287: 1019-22.

[11] Castañeda L, Maldonado A, Cheang-Wong JC, Terrones M and Olvera $\mathrm{M}$ de la $\mathrm{L}$. Composition and morphological characteristics of chemically sprayed fluorine-doped zinc oxide thin films deposited on Si(100). Phys B 2007; 390: 10-6.

[12] Kaid MA and Ashour A. Preparation of $\mathrm{ZnO}$-doped Al films by spray pyrolysis technique. Appl Sur Sci 2007; 253: 3029-33.

[13] Wu JJ, Wen $\mathrm{HI}$, Tseng $\mathrm{CH}$ and Liu SC. Well-aligned $\mathrm{ZnO}$ nanorods via hydrogen treatment of $\mathrm{ZnO}$ films. Adv Funct Mater 2004; 14: 806-10.

[14] Groenen R, Creatore M and van de Sanden MCM. Dry etching of surface textured zinc oxide using a remote argon-hydrogen plasma. Appl Surf Sci 2005; 241: 321-5.

[15] Bian JM, Li XM, Gao XD, Yu WD and Chen LD. Deposition and electrical properties of $\mathrm{N}$-In codoped $p$-type $\mathrm{ZnO}$ films by ultrasonic spray pyrolysis. Appl Phys Lett 2004; 84: 541-3.

[16] Ye HB, Kong JF, Shen WZ, Zhao JL and Li XM. Origins of shallow level and hole mobility in codoped $p$-type $\mathrm{ZnO}$ thin films. Appl Phys Lett 2007; 90: 102115.

Received: February 6, 2009

Revised: April 03, 2009

Accepted: April 6, 2009

(c) Chen and Tien; Licensee Bentham Open.

This is an open access article licensed under the terms of the Creative Commons Attribution Non-Commercial License (http://creativecommons.org/licenses/by$\mathrm{nc} / 3.0 /$ ) which permits unrestricted, non-commercial use, distribution and reproduction in any medium, provided the work is properly cited. 